\title{
The Natural Classification of Ferns as a Study in Evolutionary Methods. ${ }^{1}$
}

\author{
By Prof. F. O. Bower, F.R.S.
}

I $\mathrm{N}$ the light of evolutionary theory the object of a natural classification of living things has ceased to be a mere catalogue, useful primarily for the recognition and accurate designation of genera and species. Such a classification is now understood to express, at least in some degree, the evolutionary relations of the organisms classified, though still it may be far from fulfilling its theoretical end. Kin will take place near to kin, and if the relationships be truly apprehended, the whole grouping of different forms will be such as to seriate them, so that those earlier in historical origin should precede those of later appearance. The series would lead from presumably primitive to presumably derivative types. But naturally a simple linear series, such as any catalogue must show, cannot adequately portray the highly complex relations of any wellrepresented group. Moreover, such relations are apt to be so obscured by the extinction of intermediate forms that, though this might at first sight appear to simplify the problem, it at the same time increases greatly the difficulty in recognising affinities, and often makes any definite opinion on relationship highly problematical.

In the face of such drawbacks many are disposed to regard the problem of natural classification as hopeless : and the results attained may appear to be mere expressions of personal bias. Moreover, the divergences of opinion expressed by different experts in the investigation of the same group are sometimes so great as to forfeit confidence in their methods. The critic may then conclude that the materials available for inductive argument are too disconnected, and positive data too deficient to lead to any satisfactory result. However true this may actually be, the demand may still be made that at least the classification adopted for any given group shall not violate, but rather accord with such settled conclusions of affinity as are founded upon an adequate field of observation comparatively treated. The wider the area of observation the more probable will it become that the grouping based upon it will be correct. This is indeed the theoretical basis of any classification that can be regarded as natural.

Many groups of plants, comprising at the present day numerous genera and species, appear so highly standardised as to give little scope for such treatment. The differences that they show are relatively minute, while in the absence of a consecutive geological record of their past history it may appear impossible to rank those differences in any probable phyletic sequence. This is the condition of the Angiosperms as a whole: consequently little headway has yet been made in their phyletic grouping: while opinions are by no means in full accord as to what characters are to be held for them as primitive, or as derivative. But it is otherwise with the Filicales. There are many thousand species of living ferns, distributed in more than a hundred well-marked genera. The range of variable characters which may serve for their comparison is wide: while the class is represented with a more or \footnotetext{
${ }^{1}$ Substance of three lectures delivered at the Royal Institution, May 21 .
28 , and June 4 .
}

less consecutive history back to the Palæozoic age. These facts at once suggest that the class of ferns would provide material suitable for a searching experiment in the methods upon which a natural classification may be based.

We have seen that in order to obtain a stable result it is desirable to extend the comparison over a wide area of fact. The weakness of early groupings for the ferns has been that the area of comparison was too narrow. It involved chiefly the external form, and the sorus and sporangia, while anatomy and the characters of the gametophyte were scarcely used at all ; nor was the palæontological evidence taken into account. Though naturally the features of the sporophyte, being more elaborate and also more varied, still take the prior place, all variable features should be used. In respect of each the limits of variability must be defined, and the question considered whether one extreme or the other should be regarded as primitive. Here a comparison with related fossils becomes important, and often indeed it is decisive, as in the conclusion that the Eusporangiate type is more primitive than the Leptosporangiate.

There are already twelve criteria of phyletic comparison in use in ferns, and others may probably emerge later. They are: (I) external form of the shoot; (2) architecture and venation of the leaf ; (3) initial constitution as shown by apical segmentation; (4) the vascular system ; (5) dermal appendages ; (6) position and structure of the sorus ; $(7)$ indusial protections: (8) character of the sporangium; (9) spore-output; (Io) morphology of the prothallus ; (II) the position and structure of the sex-organs ; (I2) embryology. In respect of all of these, but naturally in varying degree, it is possible to distinguish a type that is held to be relatively primitive, from that which is derivative; moreover, so far as comparison with related fossils is possible, the palæontological sequence may be taken as a check upon conclusions, since its data are drawn from the most positive source that is available in comparative morphology. Further, it is found in the Filicales that the results of comparison, thus checked, run substantially parallel in respect of the several criteria upon which the comparisons are based. Exceptions do as a matter of fact occur; but the marked preponderance of parallel progression in respect of features so dissimilar as, for example, sporangia and antheridia, dermal appendages, conducting tissue, and spore-output, gives added confidence to the application of a comparative method so broadly based and so adequately checked.

From materials such as these it has been possible to draw up a verbal specification of a type which would embody all the relatively primitive features, and thus it might be visualised as a common archetype, which should represent something like that source from which we may presume that the class of ferns may ultimately have sprung. The specification would comprise an upright radial shoot, perhaps rootless, and forking equally if it branched at all ; the distinction of axis and leaf ill-defined; the leaf, if recognisable as such, long

No. 2908 , VOL. I I 6] 
stalked, forking, with its segments narrow, and separate one from another; the general cellular construction robust, and without a single initial cell in the several parts; the conducting system consisting of simple tracts with solid xylem-core; the surface bare, or with simple hairs; the sporangia solitary, distal, and relatively large ; the spores numerous in each sporangium, and all alike ; and the opening mechanisms of the sporangia not highly organised. Naturally, since the prothalli are not as a rule preserved as fossils, little help is derived in checking the comparisons of the gametophyte; and it is omitted in the specification, which applies only to the sporophyte.

If the above specification be compared with the actual features displayed by the fossils of the Rhynie Chert, so beautifully revealed by Dr. Kidston and Prof. Lang, it will be seen that a substantial similarity exists. It is not suggested that any one of the Rhynie fossils itself represents an ancestor of the ferns. What does appear is that, among the vegetation of the earliest adequately known land flora, there existed plants which shared those leading features of the sporophyte which wide comparison of the ferns, living and fossil, has led us to regard as primitive for them.

Starting from such a source, which is not, as a matter of fact, far removed from what is actually seen in the extinct Botryopterideæ, a general advance may be traced through the ages, culminating in the modern Leptosporangiate ferns. The leading features of progression consist in departure from the upright habit, and equal dichotomous branching of axis and leaf; progressive webbing of the leaf-segments and adoption of netted venation; elaboration and progressive disintegration of the conducting tracts ; substitution of flattened scales for simple hairs; transit of sori from distal or marginal to superficial positions; passage from the simple sorus with sumultaneous sporangia, to a gradate or a mixed succession of them; elaboration but often also a final abortion of indusial coverings ; a progressive diminution of the individual sporangium, with corresponding increase of their numbers, and of the precision of their ejaculating mechanisms ; finally, a diminution of the spore-output from each, from many thousands to definite numbers such as $64,48,32,16,8$, or even in extreme cases to a single one. These progressions run substantially parallel, and accompany a progressive fining down of structure from the grosser Eusporangiate to the more delicate Leptosporangiate type.

Such evolutionary progression, traced by wide comparison in respect of many criteria, and checked by reference to the palæontological record, which in the ferns is both ample and consecutive, may be expected to yield material for argument as to the methods of evolution. In particular it makes possible views involving the essential factor of geological time, so often omitted or wholly forgotten in the evolutionary discussions of the moment. Between the Devonian Period and the present day there is spread out before us the whole drama of fern-evolution, including the changes profusely polyphyletic, embodied in the previous paragraph. We may fix our attention especially upon two marked features upon which the series throws light, namely, the slide of the sorus from the margin to the surface of the widening leaf, and the progressive elaboration of the vascular tissue with increasing size of the part it traverses. Evidence of progress in respect of both of these may be traced not only in the race, where the results are found to be hereditarily fixed, but also in some degree in the individual life, where they are seen to be still plastic.

The shifting of the sorus from the margin to the surface of the expanded leaf gives the biological advantage of protection from direct insolation during development. In some families, such as the Marattiaceæ, Gleicheniaceæ, and Cyatheaceæ, and in Todea, it happened early in geological history, and became hereditarily fixed with a high degree of uniformity. In others, as in the Schizæaceæ, Hymenophyllaceæ, and Dicksoniaceæ and in Osmunda, the primitive marginal position was retained. In some the transition from a marginal to a superficial position may be seen actually in progress, as in the Dennstædtiinæ and Pteridaceæ. The transition may be held as adaptive, and the steps of the adaptation may actually be followed in the individual development in such genera as Dennstædtia or in Pteridium. Such facts, the details of which will be found fully described elsewhere, ${ }^{\mathbf{1}}$ suggest that a widespread and polyphyletic phenomenon of adaptation is before us. It may be described as a slide of the sorus from the margin to the lower surface, which is clearly a biological adaptation. The genera quoted show that it is actually progressive in the individual development. The evidence suggests very strongly that there has been a widespread inheritance of a character primarily acquired by biological adaptation in the individual, and that it has become fixed as a heritable character not once only but repeatedly. The whole period of geological time from the Devonian onwards has been available for the process, which has happened in some phyla early, in others late, and is in some individual living ferns caught actually in the plastic or nascent state.

A similar argument may be advanced in relation to the progressive expansion and disintegration of the conducting tracts in ferns, which appears to be closely connected with the limiting factor of size, and the adjustment of the proportion of surface to bulk in an enlarging organism. The progressive expansion, elaboration, and even disintegration may be traced in perfection in the ontogeny of such ferns as Gleichenia pectinata, Pteris podophylla, or Plagiogyria. The elaborated result has become hereditarily fixed with characteristic differences in detail in many distinct races of ferns. The resulting structure provides features sufficiently stable to serve for far-reaching comparison.

Such arguments and such conclusions will of course be met by the objection that they traverse the doctrine of the non-inheritance of acquired characters. But it needs to be stated that the structural basis for this doctrine, however it may apply in animals, has no validity in the plant-body. In them there is no early segregation of somatic from propagative cells. These remain indistinguishable until a late state of individual development. In the absence of such structural segregation for plants, and in view of the positive evidence above advanced, we appear to be justified in concluding that in plants the distinction between fluctuating variations and mutations is not absolute.

2 Bower, F. O., "The Ferns," vol. i., Cambridge University Press, r923.

NO. 2908, VOL. I 16 ] 
In other words, characters that are seen to be adaptive in the individual life are apt to become hereditarily fixed; and in the progress of geological time this has happened repeatedly.

The impressive address of Sir Francis Darwin as president of the British Association in 1908 in Dublin should be recalled. The observations and conclusions relating to ferns which have been acquired in recent years appear to be susceptible of interpretation only through some form of mnemic theory, such as he there disclosed. It is not only in the moral world, but perhaps also in the physical frame of living things that the methods of the importunate widow produce their result ; and this will become the more plain where, as in the study of the ferns, the whole period of geological time from the Devonian Period onwards is available for the method to produce its structural effect. In recent discussions, too much stress has been laid upon the failure or success of laboratory experiments, which have extended at most over only a few years. Here in the ferns we see evidence derived from experiments carried on naturally and continuously since the Palæozoic age : and they indicate that adaptive characters are heritable. Preference should surely be given to those results which appear without any narrow timelimit. These show that, in the language of the mnemic theory, engrams are imprinted upon the propagative cells. The impress of an engram in ordinary life may be, and probably is, a relatively rare event. The difficulty in producing satisfactory evidence of the inheritance of acquired characters in brief laboratory experiments in itself indicates a high resistance of germ-cells to their reception. But prolonged comparative study of ferns, with their long geological history taken into account as a check upon its results, appears to justify the view that in them the difference between fluctuating variations and mutations is not absolute. It indicates rather that characters acquired by adaptation in the individual life may become hereditarily fixed if secular time be available.

\section{The International Research Council.}

$\mathrm{T}$ HE International Research Council held its third meeting at Brussels in the Palais des Académies on July 7 and the two following days. The first meeting took place six years ago, in July I9r9, when the statutes of the Council were adopted, and steps were taken to form the Unions of Astronomy, Geodesy and Geophysics, Chemistry, Mathematics, and Radiotelegraphy. The second meeting was held in July I922, when some additional countries were invited to join the Council, and the formation of the Unions of Geography, Physics, and of the Biological Sciences was agreed to.

Since the second meeting nine countries have joined the Council, so that the number of adhering countries up to the present time is twenty-nine, to which Latvia and Tunis have now to be added, having been admitted at this meeting: thus the total membership is now thirty-one. Of this total membership, however, only seventeen were represented on this occasion at Brussels, namely: Belgium, Czechoslovakia, Denmark, Egypt, France, Great Britain, Holland, Italy, Japan, Morocco, Norway, Poland, the Union of South Africa, Spain, Sweden, Switzerland, and the United States. The votes assigned to each country depend on its population, and the total number of votes controlled by the delegates was 52 .

It was reported to the Council that the former International Seismological Association had been dissolved, with the assent of all the countries who were members of the Association. It was proposed that the Council should accept responsibility for such of the property of the Association as had been taken over, and this was approved. The work which this Association formerly carried out is now undertaken by the Section of Seismology in the International Union of Geodesy and Geophysics.

The most important business that was before the Council related to certain modifications of the statutes which had been proposed by Australia, by Denmark and Holland, by Sweden and by Switzerland. All of these, though differing slightly in form, had for their object the removal of the restrictions which now limit the membership of the Council and the Unions related to ft to those nations who joined in 1918 , and others who have since been invited to join or have been elected under the existing statutes; these embrace only the Allies and neutrals of the War period, I914-1918, the Central Powers being excluded. At the second meeting of the Council in 1922 a proposal was made to remove this restriction, but at that time it was not considered advisable to amend the statutes, and no action was then taken.

The procedure to be followed in modifying a statute lays down that " no change shall be made in the terms of the Convention except with the approval of twothirds of the votes of the adhering countries." According to the president's calculation, the rule required 53 votes, so that even if a unanimous vote of all the delegates present had been obtained for any of the proposals, it would not have effected a valid change of statute. Thus although there was a majority of votes in favour of the changes proposed by Holland and Sweden, the statutes could not be altered. The situation, therefore, must remain as it was until the Council at another meeting comes to a different decision on this question, or agrees to modify the statute which requires a two-thirds majority of the votes, not merely of the countries present but of all the countries which belong to the Council. In the meantime the Executive Committee may by correspondence obtain a more representative opinion from all the adhering countries, for the statutes permit a country not represented by a delegate to vote by post.

The further proposal, submitted by France and Belgium, that membership of the League of Nations should qualify a country to be elected was not generally acceptable, and was therefore not adopted.

This result is in every way most unfortunate for international science: not only does it postpone the time when the Research Council will be truly international, but it also raises the question whether, as things stand, it will be possible to carry out the modification of any statute until the end of the present Convention in I93I. A full attendance of all the countries belonging to the Council at any meeting can scarcely be counted upon, though the votes of all of

No. 2908, vOL. I I 6$]$ 